\title{
Mitral Valve Repair with Artificial Chordae for Posterior Leaflet Disease
}

\author{
Yohsuke Yanase ${ }^{1 *}$, Akihito Ohkawa ${ }^{1}$, Junji Nakazawa ${ }^{1}$, Toshiyuki Maeda ${ }^{1}$, Shuichi Naraoka ${ }^{1}$, \\ Satomi Inoue ${ }^{1}$, Yukihiro Niida ${ }^{2}$
}

${ }^{1}$ Departments of Cardiovascular Surgery, Hokkaido Prefectural Kitami Hospital, Hokkaido, Japan

${ }^{2}$ Departments of Anesthesiology, Hokkaido Prefectural Kitami Hospital, Hokkaido, Japan

Email: *yanasey@sapmed.ac.jp

How to cite this paper: Yanase, Y., Ohkawa, A., Nakazawa, J., Maeda, T., Naraoka, S., Inoue, S. and Niida, Y. (2018) Mitral Valve Repair with Artificial Chordae for Posterior Leaflet Disease. World Journal of Cardiovascular Surgery, 8, 117-125. https://doi.org/10.4236/wjcs.2018.87011

Received: June 4, 2018

Accepted: July 14, 2018

Published: July 17, 2018

Copyright ( 92018 by authors and Scientific Research Publishing Inc. This work is licensed under the Creative Commons Attribution-NonCommercial International License (CC BY-NC 4.0). http://creativecommons.org/licenses/by-nc/4.0/ (c) (i) (8) Open Access

\begin{abstract}
Background: Recently, the concept of "Respect rather than resect" has been proposed in an attempt to restore mitral valve function. We investigated the results of mitral valve repair for posterior leaflet disease. Methods: Between April 2008 and July 2017, mitral valve repair was performed in 78 cases at our facility. Among them, 37 cases were analyzed. We divided patients into three groups according to the repair techniques used: artificial chordae technique, which uses the anchoring-technique and measured tube technique (Group A, 23 cases), resection and suture technique (Group R, 10 cases), and artificial chordae together with resection and suture technique (Group AR, 4 cases), and compared their postoperative outcomes. Results: Residual postoperative mitral regurgitation (MR) grade in groups $A, R$ and $A R$ at discharge were 0.3 $\pm 0.4,0.8 \pm 0.9$ and $0.0 \pm 0.0(\mathrm{p}=0.07)$, respectively. Mitral valve areas $\left(\mathrm{cm}^{2}\right)$ in groups $A, R$ and AR were $3.2 \pm 0.6,2.9 \pm 0.6$ and $3.0 \pm 0.6(p=0.47)$, respectively. Freedom from severe MR at 5 years postoperatively was seen in $91.7 \%, 90 \%$ and $100 \%(\mathrm{p}=0.92)$ in groups $\mathrm{A}, \mathrm{R}$ and AR, respectively. Conclusions: There was no significant difference in postoperative outcomes, as assessed echocardiographically, between the artificial chordae technique and resection and suture technique. The results of all repair techniques were satisfactory.
\end{abstract}

\section{Keywords}

Mitral Valve Regurgitation, Mitral Valve Repair, Artificial Chordae, Heart Valve Diseases

\section{Introduction}

Currently, mitral valve repair is the standard procedure for mitral valve regurgi- 
tation (MR), because it is superior to mitral valve replacement in terms of restoration of cardiac systolic function and does not require postoperative anticoagulant therapy. Several techniques are used for mitral valve repair. Among them, the French correction advocated by Carpentier [1], which involves repair using resection and suture of the mitral valve, and the American correction advocated by Lawrie [2], which uses artificial chordae, are popular basic techniques for mitral valve repair. For posterior mitral leaflet disease, although the resection and suture technique is considered the standard, it is associated with certain problems, such as change in valve geometry following resection and with scarring during healing followed by thickened or stiffened. Hence, Perier advocated the "Respect Rather than Resect" approach [3] [4]. Perier's repair concept involves sparing the mitral valve without performing resection. The mitral valve repair technique has matured in recent years, such that mitral valve repair using the artificial chordae technique is currently relatively easily performed. Hence, we treat posterior mitral leaflet prolapsing using the modified artificial chordae technique. Furthermore, Choi, et al. suggest that artificial chordae repair is superior to resection and suture technique in terms of leaflet mobility and coaptation evaluated by their virtual mitral valve repair simulation [5]. So, we compared the results of this artificial chordae technique for posterior mitral leaflet diseases with those of the resection and suture technique in this study.

\section{Material and Methods}

From April 2008 to July 2017, we performed 78 cases of mitral valve repair. Among them, 44 procedures were performed for repair of posterior mitral valve disease (active endocarditis and repair of only anterior mitral valve disease were eliminated). Of those, 37 cases without 7 cases (edge to edge repair: 2, unsuccessful repair: 5) were analyzed. We divided the 37 patients into three groups according to the repair technique used, as follows artificial chordae technique group (Group A, 23 cases), resection and suture technique group (Group R, 10 cases) and both artificial chordae technique and resection and suture technique used group (Group AR, 4 cases). The study was approved by the institutional review board.

\subsection{Surgical Procedure}

Following establishment of cardiopulmonary bypass via a full median sternotomy, the ascending aorta and superior and inferior vena cava were directly cannulated, the ascending aorta was cross-clamped, and antegrade and retrograde cardioplegic solution was injected. The mitral valve was exposed via a conventional left atriotomy.

After placing sutures (2-0 polyester) along the mitral annulus, the mitral valve configuration and the prolapse site were assessed using saline injection to the left ventricle. Then, the mitral valve was repaired by one of the following techniques. And then, ring annuloplasty was performed with a semi-rigid full ring of the 
same size as the anterior leaflet height. Valve reconstruction was evaluated using the saline test to determine the appropriateness of the resultant valve morphology and position of the closure line.

\subsection{Artificial Chordae Technique (Figure 1)}

An anchor consisting of a CV-2 ePTFE (Gore-Tex) suture with pledget (Gore-Tex; W.L. Gore \& Associates, Flagstaff, AZ, USA) was attached to the top of papillary muscle. A CV-5 Gore-Tex suture was then passed through the anchor (anchoring technique). Next, the CV-5 Gore-Tex suture was passed through a cut 12 Frazier suction tube (Nipro Corporation, Osaka, Japan) and attached to the edge of the prolapsed mitral valve leaflet. The length of the cut tube was determined by measuring the length of near healthy native chordae as a reference. This method constitutes the measured tube technique [6]. With the aid of the cut tube, the proper length of the chordae was fixed when the suture was tied. Finally, the tube was carefully removed. In this technique, if additional artificial chordae are required, they can be easily attached using the CV-2 anchor.

\subsection{Resection and Suture Technique}

We used triangular or quadrangular resection, depending on the size of the prolapsed area. If the prolapse area was small, triangular resection was performed.

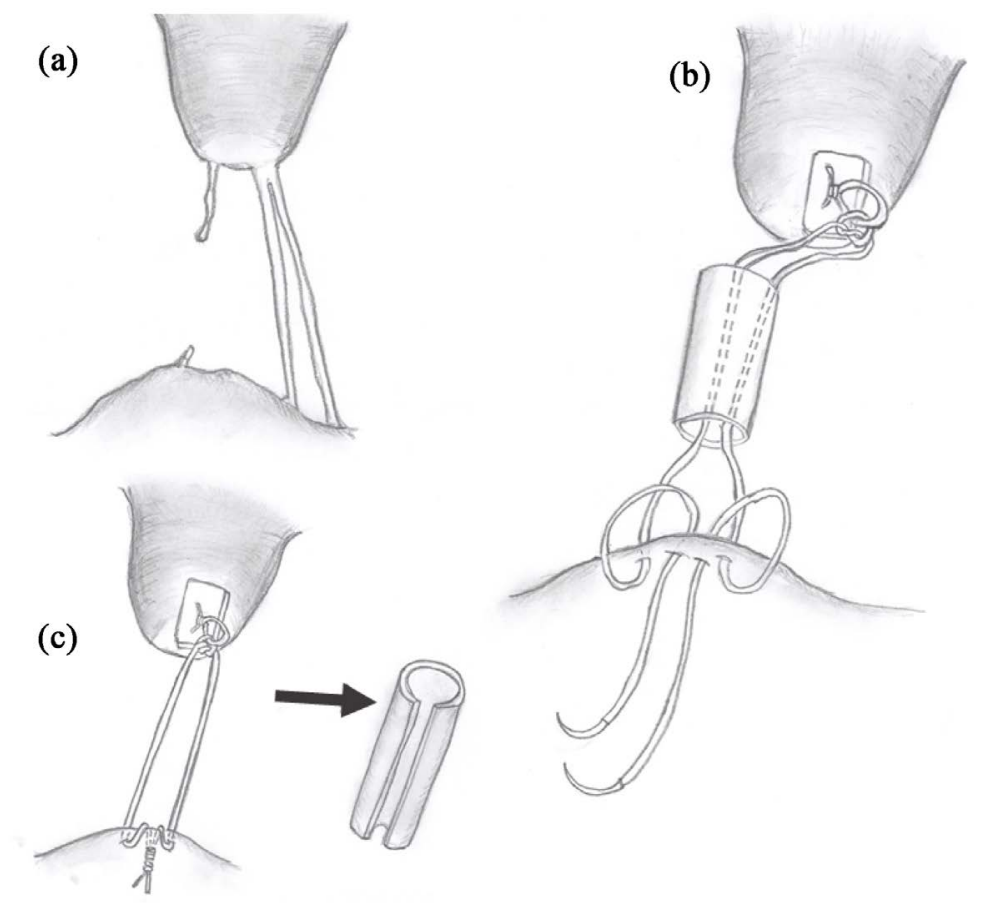

Figure 1. Mitral valve repair with insertion of artificial chordae. (a) The basal chordae of the posterior mitral leaflet was ruptured; (b) Anchoring technique with the measured tube technique. A CV-2 Gore-Tex suture was attached as an anchor to the papillary muscle. After a CV-5 Gore-Tex suture was inserted through the anchor and the cut tube, it was attached to the prolapsing posterior leaflet; (c) The CV-5 Gore-Tex suture was tied and fixed to the prolapsing leaflet, following which the tube was removed (Gray arrow). 
After resecting the prolapsed leaflet, it was repaired using interrupted with 5-0 polypropylene suture. If there was extensive prolapse, quadrangular resection with annular plication using 2-0 polyester sutures was performed.

\subsection{Artificial Chordae Together with the Resection and Suture Technique}

We sometimes added artificial chordae when the resection and suture was not enough to repair. We also additionally performed resection and suturing if a minor residual prolapse existed at a separate location from the region of attachment of the artificial chordae.

\subsection{Echocardiography}

We performed echocardiographic evaluations at discharge, 3, 6 and 12 months postoperatively, and every year thereafter. Mitral valve area (MVA) was calculated using the pressure half-time (PHT) method. Mean transmitral pressure gradient (MPG) was determined using continuous wave Doppler echocardiography. The severity of MR was classified as none or trivial (MR area $\leq 2.0 \mathrm{~cm}^{2}$; grade 0 ), mild (MR area $>2.0, \leq 4.0 \mathrm{~cm}^{2}$; grade 1), moderate (MR area $>4.0, \leq$ $6.0 \mathrm{~cm}^{2}$; grade 2), moderately severe (MR area $>6.0, \leq 8.0 \mathrm{~cm}^{2}$; grade 3 ) and severe (MR area $>8.0 \mathrm{~cm}^{2}$; grade 4$)$.

\subsection{Statistical Analysis}

All values are expressed as means \pm standard deviation. Between groups comparisons were analyzed using one-way ANOVA, $\chi^{2}$ test and Kaplan Meier analysis. $\mathrm{P}<0.05$ was considered statistically significant.

\section{Results}

The characteristics of patients in groups A, R and AR are shown in Table 1. There were no significant differences in baseline characteristics between groups. The patients' operative data is shown in Table 2. The sizes of the artificial rings $(\mathrm{mm})$ in groups $\mathrm{A}, \mathrm{R}$ and $\mathrm{AR}$ were $31.4 \pm 2.0,30.0 \pm 3.3$ and $32.0 \pm 1.6(\mathrm{p}=$ $0.24)$, respectively. There were no significant differences in terms of the concomitant procedures performed in the three groups. Regarding the prolapse site of the posterior mitral leaflet, $\mathrm{P} 2$ and $\mathrm{P} 3$ were the most common sites of prolapse in all groups. In group $\mathrm{A}$, one patient died because of low output syndrome in the perioperative period. In group $\mathrm{R}$, two patients required permanent pacemaker implantations because of bradycardia with atrial fibrillation. Postoperative bleeding occurred in one patient each in groups $\mathrm{R}$ and AR. Bleeding in the patient in group AR resulted in post-resuscitation encephalopathy. Mediastinitis and pneumonia did not occur in any of the patients. More than half of the patients underwent surgery without blood transfusion.

The MR grade at discharge in groups $\mathrm{A}, \mathrm{R}$ and $\mathrm{AR}$ were $0.3 \pm 0.4,0.8 \pm 0.9$ and $0.0 \pm 0.0(\mathrm{p}=0.07)$, respectively (Table 3$)$. The MVA at discharge in groups A, R and AR were $3.2 \pm 0.6,2.9 \pm 0.6$ and $3.0 \pm 0.6 \mathrm{~cm}^{2}(\mathrm{p}=0.47)$, respectively. 
Table 1. Patient characteristics.

\begin{tabular}{ccccc}
\hline & Group A $(\mathrm{n}=23)$ & Group R $(\mathrm{n}=10)$ & Group AR $(\mathrm{n}=4)$ & p-value \\
\hline Gender (Male) & 19 & 7 & 2 & 0.33 \\
Age (years) & $65.9 \pm 12.6$ & $68.4 \pm 7.9$ & $63.3 \pm 14.3$ & 0.74 \\
BSA (m $\left.{ }^{2}\right)$ & $1.62 \pm 0.18$ & $1.62 \pm 0.12$ & $1.61 \pm 0.12$ & 1.00 \\
NYHA & $2.1 \pm 0.5$ & $2.0 \pm 0$ & $1.8 \pm 0.5$ & 0.37 \\
MR grade & $3.9 \pm 0.3$ & $3.7 \pm 0.5$ & $4.0 \pm 0$ & 0.26 \\
LVEF (\%) & $61.5 \pm 9.1$ & $64.6 \pm 9.4$ & $69.2 \pm 1.7$ & 0.24 \\
HT & 11 & 6 & 3 & 0.55 \\
CAD & 2 & 4 & 0 & 0.05 \\
CVD & 2 & 1 & 0 & 0.81 \\
PAD & 1 & 1 & 0 & 0.71 \\
CKD & 7 & 4 & 1 & 0.82 \\
Respiratory & 7 & 1 & 0 & 0.23 \\
dysfunction & 4 & 1 & 0 & 0.60 \\
PAF & 6 & 4 & 1 & 0.71 \\
CAF & & & & \\
\hline
\end{tabular}

BSA: body surface area, NYHA: New York Heart Association classification, MR: Mitral regurgitation, LVEF: left ventricular ejection fraction, HT: Hypertension, CAD: Coronary artery disease, CVD: cerebrovascular disease, PAD: Peripheral artery disease, CKD: Chronic kidney disease, PAF: paroxysmal atrium fibrillation, CAF: chronic atrium fibrillation.

Table 2. Operative data.

\begin{tabular}{ccccc}
\hline & $\begin{array}{c}\text { Group A } \\
(\mathbf{n}=23)\end{array}$ & $\begin{array}{c}\text { Group R } \\
(\mathbf{n}=10)\end{array}$ & $\begin{array}{c}\text { Group AR } \\
(\mathbf{n}=4)\end{array}$ & p-value \\
\hline Artificial ring & 23 & 10 & 4 & - \\
Physio II & 9 & 8 & 2 & - \\
MEMO3D & 13 & 2 & 2 & - \\
Cosgrove & 1 & 0 & 0 & - \\
Average ring size (mm) & $31.4 \pm 2.0$ & $30.0 \pm 3.3$ & $32.0 \pm 1.6$ & 0.24 \\
Average number of artificial chordae & $2.0 \pm 0.8$ & 0 & $1.5 \pm 0.6$ & - \\
Anterior mitral leaflet disease & 12 & 4 & 2 & 0.81 \\
Concomitant procedure & 18 & 8 & 2 & 0.45 \\
AVR & 2 & 1 & 1 & - \\
TAP & 18 & 8 & 2 & - \\
Maze procedure & 8 & 2 & 1 & - \\
CABG & 2 & 4 & 0 & - \\
Ascending aorta replacement & 1 & 1 & 0 & -
\end{tabular}

AVR: Aortic valve replacement, TAP: Tricuspid annuloplasty, CABG: Coronary artery bypass grafting.

The MPGs at discharge were $3.1 \pm 1.8 \mathrm{mmHg}, 3.3 \pm 1.1 \mathrm{mmHg}$, and $2.0 \pm 1.0$ $\mathrm{mmHg}(\mathrm{p}=0.43)$ in groups $\mathrm{A}, \mathrm{R}$ and $\mathrm{AR}$, respectively. MR grade, MVA and MPG did not significantly differ between the three groups. At one year postoperatively, as well, echocardiography data on MR grade, MVA and MPG did not 
Table 3. Echocardiography data after the operation.

\begin{tabular}{ccccc}
\hline & Group A & Group R & Group AR & p-value \\
\hline $\begin{array}{c}\text { MR grade } \\
\text { At discharge }\end{array}$ & $0.3 \pm 0.4$ & $0.8 \pm 0.9$ & $0.0 \pm 0.0$ & 0.07 \\
After 1 year & $0.7 \pm 1.1$ & $0.7 \pm 0.5$ & $0.8 \pm 0.3$ & 0.98 \\
$\begin{array}{c}\left.\text { MVA (cm }{ }^{2}\right) \\
\text { At discharge }\end{array}$ & $3.2 \pm 0.6$ & $2.9 \pm 0.6$ & $3.0 \pm 0.6$ & 0.47 \\
After 1 year & $2.6 \pm 0.4$ & $2.7 \pm 0.6$ & $2.4 \pm 0.7$ & 0.60 \\
MPG (mmHg) & $3.1 \pm 1.8$ & $3.3 \pm 1.1$ & $2.0 \pm 1.0$ & 0.43 \\
At discharge & $3.5 \pm 1.6$ & $4.2 \pm 2.4$ & $4.8 \pm 4.0$ & 0.55 \\
After 1 year & &
\end{tabular}

MR: mitral regurgitation, MVA: mitral valve area, MPG: mean transmitral pressure gradient.

significantly differ between the three groups. Overall survival rate at 5 years postoperatively in groups A, R and AR were $95.7 \%, 100 \%$ and $75 \%(p=0.32)$, respectively. Cardiac disease-related death did not occur in any of the groups. Freedom from severe MR at 5 years postoperatively was seen in $91.7 \%, 90 \%$ and $100 \%$ of patients in groups $A, R$ and $A R$, respectively (Figure 2), indicating no statistically significant difference between the three groups $(p=0.92)$. In terms of MR recurrence, one case in group A experienced recurrence due to new degenerative changes in the anterior mitral leaflet, while dehiscence of the suture line occurred in one case in group R. Both cases were treated with mitral valve replacement.

\section{Discussion}

The resection and suture technique based on the French correction advocated by Carpentier [1] is widely performed for surgical repair of posterior mitral leaflet prolapse. In this procedure, quadrangular resection of the prolapse area is performed and the edge of the cut leaflet is sutured with annular plication. If the height of the remnant is excessively tall, a sliding technique should be added [7]. Although a high degree of surgical skill is required, butterfly resection [8] [9] and hourglass resection [10] do not require annular compression sutures. Hence, their procedures may expect good hemodynamic results of the mitral valve [11]. If the prolapse area is small, triangular resection is used without annular plication [12]. Since the above techniques involve resection and suturing of the mitral valve leaflet, they carry the risk of future mitral valve stenosis. Dehiscence or thickening of the suture line is also a concern. Hence, the concept of "respect rather than resect", which involves restoring the leaflet as much as possible, has been recently advocated. By restoring the valve leaflet, its anatomical structure is maintained, so that a large mitral valve area and good hemodynamics are expected. This technique requires the use of artificial Gore-Tex chordae as the neochordae. The usefulness and durability of artificial Gore-Tex chordae in mitral valve repair for anterior mitral leaflet disease has already been demonstrated [13] [14]. 


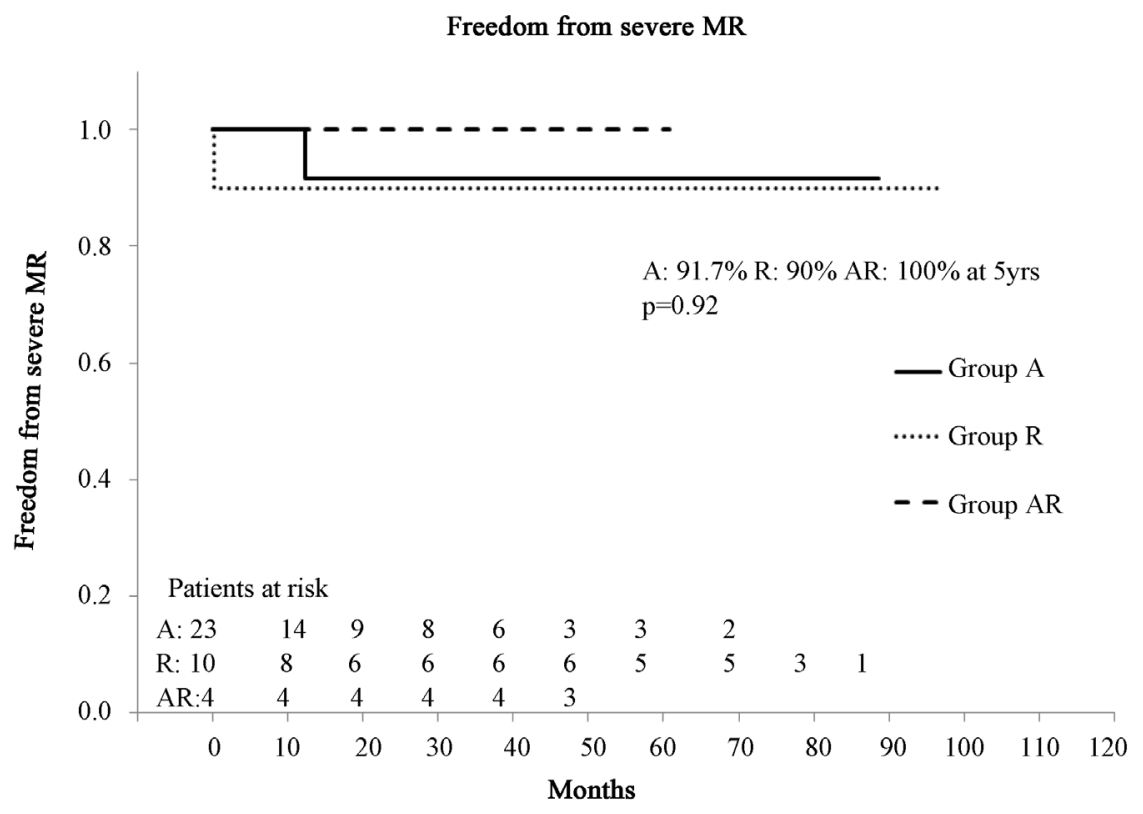

Figure 2. Freedom from severe MR. Resultant freedom from severe mitral valve regurgitation (MR) in the three groups. No significant differences were seen in the three groups at the 5-year follow up, with freedom from severe MR being seen in $91.7 \%, 90 \%$ and $100 \%$ of patients in Groups A, R and AR, respectively ( $p=0.92$ ).

Although adjustment of the appropriate artificial chordae length is reportedly difficult, the new anchoring technique and measured tube technique [6] make mitral valve repair using artificial chordae easier. The merit of the anchoring technique is that by anchoring CV-2 Gore-Tex sutures to the papillary muscle, multiple artificial chordae (CV-5 Gore-Tex sutures) can be easily attached to the mitral valve leaflet via the anchor. The benefit of the measured tube technique is that the use of a 12 Frazier suction tube cut to the same length as healthy native chordae prevents knot slippage and allows keeping the appropriate length of the chordae. Re-establishment of the artificial chordae is also easy because this technique does not involve resection of the valve leaflet. Currently, mitral valve repair has become the standard procedure for MR, which should, thus, be mastered by all cardiac surgeons. We consider the anchoring technique and measured tube technique as being safe, reliable and an easily reproducible technique. At present, we preferentially use this technique for repair of posterior leaflet disease.

Our study showed that there was no significant difference in postoperative echocardiographic data between the artificial chordae group and the resection and suture group. However, since the artificial chordae technique does not require resection of the valve leaflet, the repaired leaflet is expected to maintain its flexibility and a large mitral valve area. The report of Takai, et al. supports this theory [15]. Future studies should be performed to confirm the superiority of artificial chordae. On the other hand, the resection and suture technique, which was routinely performed at our hospital before introduction of the artificial 
chordae technique, also has good long-term results (such as durability). Further, in some cases, such as those with leaflet destruction due to infective endocarditis, or cases with excessive tissue such as with Barlow's disease, leaflet resection is a necessity. Hence, the resection and suture technique is also a clinically useful procedure.

\section{Conclusion}

Both the artificial chordae technique and resection and suture technique produce equally favorable results following mitral valve repair for posterior leaflet disease. Further long-term analyses of these techniques are needed to confirm their utility.

\section{Study Limitation}

The study cohort was small, because mitral valve prolapse is not a very common condition. Further, echocardiography could not successfully assess all the relevant parameters in our study cohort.

\section{Disclosure Statement}

The Authors declare that there is no conflict of interest.

\section{References}

[1] Carpentier, A. (1983) Cardiac Valve Surgery-The "French Correction". The Journal of Thoracic and Cardiovascular Surgery, 86, 323-337.

[2] Lawrie, G.M. (2006) Mitral Valve: Toward Complete Repairability. Surgical Technology International, 15, 189-197.

[3] Perier, P., Hohenberger, W., Lakew, F., Batz, G., Urbanski, P., Zacher, M., et al. (2008) Toward a New Paradigm for the Reconstruction of Posterior Leaflet Prolapse: Midterm Results of the "Respect Rather than Resect" Approach. The Annals of Thoracic Surgery, 86, 718-725. https://doi.org/10.1016/j.athoracsur.2008.05.015

[4] Perier, P., Hohenberger, W., Lakew, F. and Diegeler, A. (2015) Prolapse of the Posterior Leaflet: Resect or Respect. Annals of Cardiothoracic Surgery, 4, 273-277.

[5] Choi, A., McPherson, D.D. and Kim, H. (2017) Neochordoplasty versus Leaflet Resection for Ruptured Mitral Chordae Treatment: Virtual Mitral Valve Repair. Computers in Biology and Medicine, 90, 50-58. https://doi.org/10.1016/j.compbiomed.2017.09.006

[6] Matsui, Y., Kubota, S., Sugiki, H., Wakasa, S., Ooka, T., Tachibana, T., et al. (2011) Measured Tube Technique for Ensuring the Correct Length of Slippery Artificial Chordae in Mitral Valvuloplasty. The Annals of Thoracic Surgery, 92, 1132-1134. https://doi.org/10.1016/j.athoracsur.2011.03.111

[7] Perier, P., Clausnizer, B. and Mistarz, K. (1994) Carpentier "Sliding Leaflet" Technique for Repair of the Mitral Valve: Early Results. The Annals of Thoracic Surgery, 57, 383-386. https://doi.org/10.1016/0003-4975(94)91001-4

[8] Asai, T., Kinoshita, T., Nishimura, O., Kambara, A., Suzuki, T. and Matsubayashi, K. (2011) A Novel Design of Posterior Leaflet Butterfly Resection for Mitral Valve Repair. Innovations. Technology and Techniques in Cardiothoracic and Vascular Surgery, 6, 54-56. 
https://doi.org/10.1097/IMI.0b013e31820c0107

[9] Asai, T., Kinoshita, T., Suzuki, T., Shiraishi, S. and Koike, M. (2015) Early and Follow-Up Results of Butterfly Resection of Prolapsed Posterior Leaflet in 76 Consecutive Patients. The Journal of Thoracic and Cardiovascular Surgery, 149, 1296-1300. https://doi.org/10.1016/j.jtcvs.2015.01.001

[10] Sawazaki, M., Tomari, S., Izawa, N. and Ueda, Y. (2013) Hourglass-Shaped Resection Technique for Repair of Tall Mitral Valve Posterior Leaflet Prolapse. The Journal of Thoracic and Cardiovascular Surgery, 146, 275-277. https://doi.org/10.1016/j.jtcvs.2012.06.054

[11] Sawazaki, M., Tomari, S., Zaikokuji, K. and Imaeda, Y. (2014) Controversy in Mitral Valve Repair, Resection or Chordal Replacement? General Thoracic and Cardiovascular Surgery, 62, 581-585. https://doi.org/10.1007/s11748-014-0459-x

[12] Da Col, U., Di Bella, I., Bardelli, G., Koukoulis, G. and Ramoni, E. (2006) Triangular Resection and Folding of Posterior Leaflet for Mitral Valve Repair. Journal of Cardiac Surgery, 21, 274-276. https://doi.org/10.1111/j.1540-8191.2006.00231.x

[13] David, T.E. (1989) Replacement of Chordae Tendineae with Expanded Polytetrafluoroethylene Sutures. Journal of Cardiac Surgery, 4, 286-290. https://doi.org/10.1111/j.1540-8191.1989.tb00291.x

[14] Lawrie, G.M., Earle, E.A. and Earle, N.R. (2006) Feasibility and Intermediate Term Outcome of Repair of Prolapsing Anterior Mitral Leaflets with Artificial Chordal Replacement in 152 Patients. The Annals of Thoracic Surgery, 81, 849-856. https://doi.org/10.1016/j.athoracsur.2005.08.077

[15] Takai, H., Tanabe, H., Yamabe, T., Sasaki, K. and Suma, H. (2016) Midterm Outcome of Mitral Valve Repair with Artificial Chordae for Only Posterior Leaflet Disease-Comparison with the Resectional Technique in a Single Institute. Annals of Thoracic and Cardiovascular Surgery, 22, 32-37. https://doi.org/10.5761/atcs.oa.15-00153 